\title{
Erratum to: Synergistic effect and mechanism of vitamin $A$ and vitamin D on inducing apoptosis of prostate cancer cells
}

\author{
Jianjun Sha $\cdot$ Jiahua Pan $\cdot$ Ping Ping • \\ Hanqing Xuan $\cdot$ Dong Li $\cdot$ Juanjie Bo $\cdot$ \\ Dongming Liu $\cdot$ Yiran Huang
}

Published online: 21 March 2013

(C) Springer Science+Business Media Dordrecht 2013

Erratum to: Mol Biol Rep (2013) 40:2763-2768

DOI 10.1007/s11033-012-1925-0

Acknowledgement was missing in the original publication and thus needs to be read as:
This study was supported by National Natural Science Foundation of China (91129725).

The online version of the original article can be found under doi:10.1007/s11033-012-1925-0.

J. Sha $\cdot$ J. Pan $\cdot$ P. Ping $\cdot$ H. Xuan $\cdot$ D. Li $\cdot$ J. Bo $\cdot$ D. Liu Y. Huang $(\bowtie)$

Department of Urology, Renji Hospital, School of Medicine, ShanghaiJiaotong University, Shanghai 200001, China

e-mail: huangyiranhos@hotmail.com 